\title{
Das (unheimliche) Lachen Gottes in der Bibel
}

Vom Lachen Gottes ist in der Bibel nur selten die Rede. Es gehört zu den menschlichen Handlungen und Eigenschaften, die - wie etwa auch die Sexualität oder die Exkremation - nicht oder nur selten auf Gott übertragen werden. Zeigt sich daran die Humorlosigkeit der biblischen Schriftsteller und Tradenten? In der Tat gibt es in der Bibel Stimmen, die das Lachen für etwas Unfeines und Törichtes halten. «Der Tor lacht laut heraus, / der Kluge lächelt still für sich,» schreibt Jesus Sirach $(21,20)$. Und Kohelet lässt einen larmoyanten König erklären, das Lachen sei etwas Törichtes $(2,2)$.Wenig später setzt Kohelet dem aber entgegen, dass im Leben des Menschen wie das Weinen auch das Lachen seinen Platz und seine Zeit hat $(3,4)$. Wenn Weinende wieder lachen können, ist das etwas Gutes und Schönes (vgl. Psalm 126,2; Lukas 6,21).

\section{Das rücksichtslose Lachen Gottes}

Wenn aber Gott lacht, ist das für Menschen eher unheimlich. In Psalm 104,26 heisst es (nach einer möglichen Deutung des hebräischen Textes): Gott hat den Leviatan (ein Chaos-Ungeheuer, das die Ordnung der Welt und das Leben der Menschen bedroht) gebildet, um mit ihm

Ein göttliches Wesen kämpft mit einem Chaos-Ungeheuer / O. Keel, Die Welt der altorientalischen Bildsymbolik und das Alte Testament. Am Beispiel der Psalmen, Göttingen 1996.

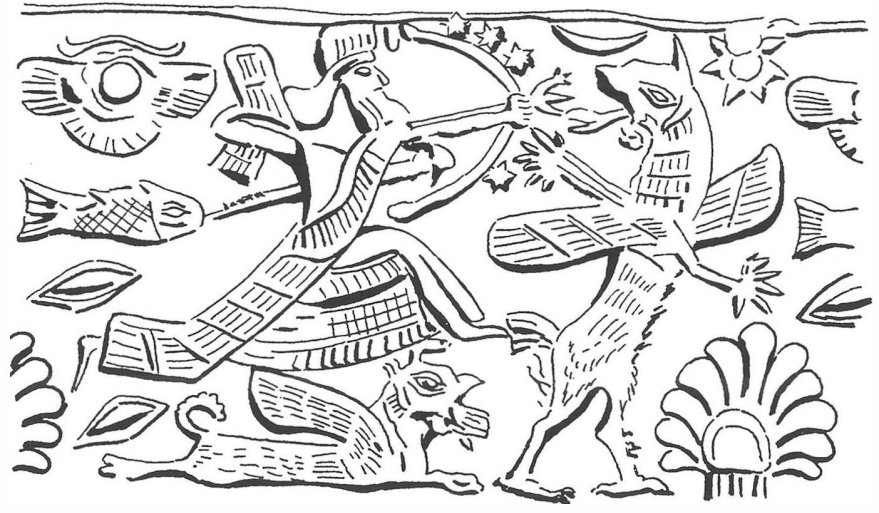


$\mathrm{zu}$ "spielen». Im Hebräischen steht hier dasselbe Wort, das an anderen Stellen mit "lachen» übersetzt wird. Was andernorts in der Bibel und in der altorientalischen Literatur als Kampf zwischen Göttern und Chaos-Mächten dargestellt ist, wird hier zu einer sportlichen Belustigung Gottes. Für die Menschen ist das auf der einen Seite beruhigend: Ernsthaft gefährdet sind die Welt und das Leben nicht, auch wenn sie bis in die Grundfesten erschüttert und vom Unheil überschwemmt werden mögen. Gott ist den Mächten des Chaos weit überlegen. Andererseits kann sich Gott aber eben auch - gerade weil er so mächtig und überlegen ist - den Spass leisten, den Leviatan zum Kampf zu reizen, die Erde erbeben zu lassen oder zu überschwemmen. Wenn dabei Menschen und Tiere auf der Strecke bleiben, nimmt er dies sozusagen als "Kollateralschaden» in Kauf.

\section{Das schadenfrohe Lachen Gottes}

Dass diese Sicht Gottes und der Welt nicht ganz so "heiter» ist, wie sie in Psalm 104 - jedenfalls auf den ersten Blick - daherkommt, macht Hiob deutlich. An einem Tag verliert er seine Kinder, seinen Besitz und seine Gesundheit, und dies nicht nur ohne eigene Schuld, sondern gerade weil er so vorbildlich "fromm und gerecht" ist, dass Gott sich vom Satan hinreissen lässt zu einer Wette über Hiobs Standfestigkeit im Leiden. In Anbetracht seines eigenen Schicksals und des unschuldigen Leidens in der Welt erklärt Hiob Gott zu einem irren Sadisten: «Schuldlose wie Schuldige vernichtet er! / Wenn seine Geissel plötzlich tötet, / so lacht er der Verzweiflung der Unschuldigen" (Hiob 9,22 f). Im Fortgang des Buches macht Hiob zwar weitere Erfahrungen mit Gott, die ihn zu einer Korrektur seines Gottesbildes führen. Seine "Anti-Theologie» in Kap. 9 bleibt aber gültig als Erinnerung daran, dass das Bild eines lachenden Gottes keineswegs harmlos und für den Menschen angenehm ist.

\section{Das zornige Lachen Gottes}

Für die einen bedrohlich, für die anderen befreiend ist das Lachen Gottes dann, wenn Gott über die vermeintliche Grösse, Stärke und Selbstsicherheit von Menschen lacht, die sich über und gegen andere erheben: kriegslustige Völker (Psalm 2,4) oder rücksichtslose Egoisten (Psalm 37,13; 59,9; Sprüche 3,34). «Der im Himmel thront, lacht, / der Herr spottet über sie. // Dann redet er sie an in seinem Zorn, / und in seinem Grimm erschreckt er sie» (Psalm 2,4f). In Anbetracht der Überlegenheit Gottes wird jedes menschliche Macht- und Imponier- 
gehabe lächerlich. Wenn Gott darüber lacht und es damit lächerlich macht, wirkt er ihm entgegen. Das Lachen Gottes bringt hier seinen Zorn zum Ausdruck.Von daher ist es verständlich, wenn sich die Menschen in der Bibel nicht nach einem lachenden Gott sehnen, sondern eher nach einem Gott, der freundlich lächelt, dessen "Angesicht leuchtet», wie es im sogenannten aaronitischen Segen heisst (Numeri 6,25).

\section{Gottesbilder: mit Vorsicht zu gebrauchen!}

Bei aller Kritik an von Menschen verfertigten Gottesbildern verzichtet die Bibel doch nicht auf sprachliche, poetische, mythische Bilder des Göttlichen - wie das Bild vom lachenden, zornigen oder lächelnden Gott. Auch solche Gottesbilder müssen kritisch geprüft werden; auch sie sind ja von Menschen gemacht. Ein Gesichtspunkt der Kritik ist die Frage, wieweit die Ambivalenz und Komplexität unserer Erfahrungen mit der Wirklichkeit in solchen Bildern anschaulich und begreiflich wird.Ein Gott, der nur freundlich, lustig und lieb ist, kann uns die gelegentliche Flucht aus einem unwirtlichen Alltag ermöglichen (oder uns den endgültigen Ausstieg aus "dieser Welt» verheissen). Fragt man aber, wieso der Alltag eigentlich so unwirtlich ist, zeigt der «liebe Gott» unweigerlich Schwächen (er kann nichts dagegen machen) oder weniger freundliche, unheimlichere Züge (er will nichts dagegen machen).

So wird ein Gottesbild, das nicht der Flucht aus einer rauhen Wirklichkeit dienen soll, sondern zu einem Leben in dieser Wirklichkeit befähigen, auch Züge des Unbegreiflichen, Unheimlichen und Widersprüchlichen enthalten müssen. Und Manches, was auf den ersten Blick wünschenswert erscheinen mag - wie das "Lachen Gottes» -, erweist sich bei näherem Zusehen als abgründig und erschreckend.Vielleicht können wir - trotz Bilderverbot - auf Gottesbilder nicht verzichten. Wer aber mit solchen Bildern spielt, verbrennt sich leicht (nicht nur) die Finger.

\footnotetext{
- Dr. Thomas Krüger ist Professor für Alttestamtentliche Wissenschaft und altorientalische Religionswissenschaft an der Theologischen Fakultät Zürich.
} 